\title{
The Whatness of Digital Accounting: Status Quo and Ways to move forward
}

\author{
Othmar Lehner*,1,2, Susanne Leitner-Hanetseder ${ }^{2}$, Christoph Eis1 $^{2}$ \\ ${ }^{1}$ Hanken School of Economics, Helsinki, Finland \\ ${ }^{2}$ University of Applied Sciences Upper Austria
}

\section{Introduction}

Digital Accounting has found its way into the everyday language used by accounting practitioners, with the Big 4 auditing companies pouring massive resources into the digitalisation of accounting processes in order to create an early-mover business advantage.

In research, digital accounting is used as summarizing term for a variety of research endeavours into the digitalisation and automatization of accounting processes based on emerging technologies (Quattrone, 2016). The existing literature deals for example with the role of digital technology in accounting and reporting (Güney, 2014; Ghasemi et al., 2011; Taipaleenmäki and Ikäheimo, 2013), the integration of the competences required in the accounting curricula (Sledgianowski et al., 2017; Janvrin and Weidenmier Watson, 2017) and the detection of fraud (Pearson and Singleton, 2008).

Already by its name, a research field of digital accounting will have to be interdisciplinary, as it includes the disciplines digital (information) technology and accounting (Lehner and Martikainen, 2019). However, due to the broadness of accounting itself, comprising financial as well as management accounting (Taipaleenmäki and Ikäheimo, 2013), insights and theories from these subfields as well as from auditing, innovation and engineering, business law, organizational theory and ethics as well as accounting education amongst others, will provide further fruitful avenues to enrich the field of digital accounting.

While this variety of related fields and theories and the related insights from particular angles certainly provides value and drives the field forward, a common, holistic understanding of the whatness of the field of digital accounting and a related research agenda that would allow to join forces and interlink the various perspectives is missing so far.

In the past, accounting information systems (AIS) have changed the way that data is collected and prepared for the decision-making by stakeholders (Neely and Cook, 2011). The further development of such systems, for example through partly-autonomous robots for process automatization, through advances in creating fully digital workflows and finally also innovative algorithms based on data-science certainly form a major part of how digital accounting needs to be understood in current research. However, most scholars would agree that digital accounting in the future will certainly be more than just collecting and processing data, as advances in artificial

* Corresponding author. 
intelligence (AI) research already predict some sort of multi-functional, cognitive capabilities and the ability to make decisions given complex scenarios. Therefore, digital transformation in accounting needs to be seen as an ongoing process that ultimately may lead to a fully autonomous accounting system (FAAS), which will be defined later in this paper. Such a fully autonomous accounting system would include (AI) based cognition and high-level decision making as special and new areas within the wider field of accounting. Of course, such developments are necessarily embedded within a larger societal change process induced amongst by a variety of technological advancements (Vial, 2019) and societal movements (Colignon and Covaleski, 1991; Englund et al., 2011; Hopwood, 1983).

With this special issue, we thus like to invite and motivate the community of scholars interested in digital accounting to collaborate, to take in the various field-specific perspectives and to finally holistically map and delineate the field of digital accounting. For this, we propose an early framework and a research agenda that may unite and guide researchers towards a holistic understanding of the field.

In addition, and for this special issue we have asked grad-students and researchers from the department of accounting at the Hanken School of Economics, Helsinki to provide their research papers and perspectives on the "whatness" of Digital Accounting.

\section{Utopian Spotlights of a Fully Autonomous Accounting}

Here we provide a selection of five spotlights on different aspects of digital accounting to illustrate the insights we have gained so far from an ongoing delphi study on this topic.

\section{Spotlight 1: Extending the customer base}

A new customer $\mathrm{X}$ in a B2B scenario sends an inquiry for a certain quantity of our top-selling product $\mathrm{A}$. The AI deploys a robot to crawl all external data sources including company-register, company web-site, social-media, banks and triangulates the findings with the response from the credit-agency. The credit-worthiness has been confirmed and starts a price calculation that includes current sales and production-capacities as well as the previously determined credit-risk. The price is confirmed by $\mathrm{X}$ and we receive a full order. Immediately, a robot transfers all data from the order as well as the previously retrieved additional data from the crawler into a newly generated customer item within the virtual data store and logs the order into the ERP subsystem.

\section{Spotlight 2: Ad-hoc reporting and decision support}

Our marketing manager receives information from a media partner that a top athlete and multiple medal winner would be available for a long-term sponsorship contract. The marketing manager sends an ad hoc request to the FAAS via voice recognition to get decision support. The FAAS assesses the effects of sponsoring on the image values and price willingness of the customers, updates the sales forecast, checks the available advertising budget or suggests budget reallocations and, taking into account a risk assessment, makes a final recommendation on the range of the rationally justifiable sponsoring amount. 


\section{Spotlight 3: FAAS-warning message}

Early in the morning the production manager arrives at the office and asks the FAAS to provide an internal status report and update in natural language by asking "What's news?". The FAAS scans all relevant real-time reports and data trends and compiles the top news. The FAAS places the focus on a warning message that requires immediate action: "Current machine sensor data indicate urgent maintenance work in a production plant". In the background, the system has already checked possible production shifts to another flexible manufacturing cell as well as outsourcing options and has determined the cost-optimal time for the upcoming maintenance work, taking into account adherence to delivery dates and maintaining a high level of customer satisfaction. The gathered data is presented as a working scenario and potential solution to the manager. After her confirmation, the FAAS automatically initiates the execution of the plan. Based on the severity of this maintenance, the FAAS classifies it as a major inspection according to current GAAP (generally accepted accounting principles), recalculates the real-time forecasts and updates the top-management reports.

\section{Spotlight 4: Valuation of a Leasing Contract using timely WACC}

Our FAAS applies AI for the extraction of lease data attributed from the contracts and for the following classification, valuation and presentation of leasing contracts in the financial reports. In addition to the classification of the leasing contract, several internal as well as external information sources are used by the FAAS to calculate the average weighted capital costs (WACC) for each contract based on the commencing dates and maturity. For this, yield rates based on the maturity as well as current risk-based equity costs are calculated. Because of differences between the various applicable, local and international accounting and taxation standards, the FAAS acts accordingly concerning the classification, recognition, measurement and reporting. The data and underlying set of applied rules is automatically transferred to the contracted auditing firm.

\section{Spotlight 5: Reflecting Strategic Decisions in the Accounting System:}

The Case of End-of-Life of a major product line

Product line $\mathrm{B}$ has seen the best of its days. With a number of product variations and related, then well-crafted cost-centres, line B was among the core lines of the company for a long time. Due to innovation and inevitable changes in the markets, the board has decided to cease line B three years ago and the sales and production transition is now complete. In an attempt to reflect these changes now in the accounting system and to clear it from any remaining clutter, the FAAS has now been tasked to take care of the necessary steps. The AI first takes into account respective regulations for financial accounting and also considers the change in demand for internal information on all levels. All data and features that need to be kept for external regulatory compliance are archived and marked with a due date for deletion, and the internal accounting structure is adapted by marking the cost-centres as obsolete, deleting all related items for possible new entries in the ERP system, adjusting the calculations for the various key performance indicators (KPIs), and by remodelling and optimising the management dash-boards to make better use of the now empty space. It then provides an update to the CFO including how the sales volumes of the discontinued line B have already been successfully transferred to the new lines by the individual customers and creates a list of recommendations for the sales team which customers might need to be better addressed as their current volumes indicate that they have replaced B by alternative products from outside of our company. 


\section{Discussing a Research Agenda in 5 Items}

We invite and want to motivate the community of scholars to collaborate and interlink the various field-specific perspectives with the ultimate aim to holistically map and delineate the field of digital accounting.

This research agenda may help to better understand the digital transformation towards a fully autonomous accounting and may also assist to make this very transformation happen by providing empirical data-based guidance to practitioners as well as policymakers. The outcome of our collective research should also inform society on the broader opportunities and threats stemming from a fully autonomous accounting and help them form an educated opinion on the implied societal changes with its ethical challenges.

The agenda is structured into the following five perspectives as follows in figure 2 .

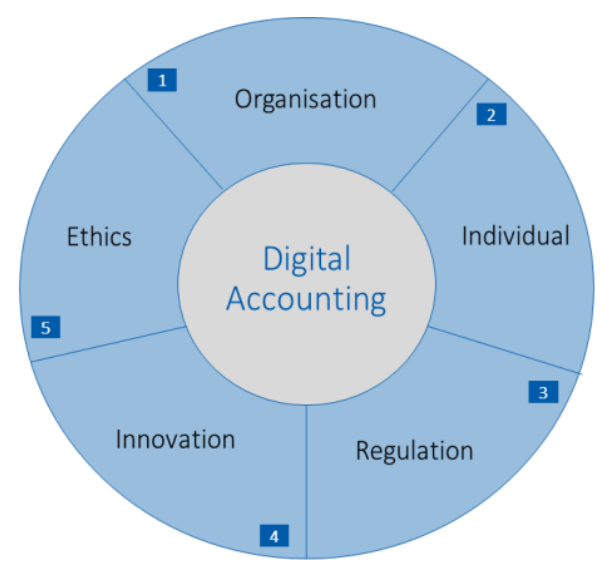

Figure 1 Perspectives on Research in Digital Accounting, source: authors

The research agenda for the field of digital accounting finally comprises five perspectives, namely organisation, individual, regulation, innovation and ethics, and potential theories within each of these perspectives are proposed.

We sincerely hope you enjoy this special issue of the ACRN Oxford Journal of Finance and Risk Perspectives on Digital Accounting, and are looking forward to your replies and comments, and to further research papers on this fascinating topic.

We would also like to extend a special thank you to Prof Minna Martikainen from the Hanken School of Economics, Helsinki for her fantastic support and co-editorship and to all the authors in this special issue from Hanken who dedicated a lot of time and ressources to come up with insights and research papers from a great variety of perspectives.

\section{References}

Belfo F and Trigo A. (2013) Accounting Information Systems: Tradition and Future Directions. Procedia Technology 9: 536-546.

Bourdieu P and Nice R. (1977) Outline of a Theory of Practice: Cambridge university press Cambridge. 
Colignon R and Covaleski M. (1991) A Weberian framework in the study of accounting. Accounting, Organizations and Society 16: 141-157.

Conrad L. (2014) Reflections on the application of and potential for structuration theory in accounting research. Critical Perspectives on Accounting 25: 128-134.

Crookes L and Conway E. (2018) Technology Challenges in Accounting and finance. Contemporary Issues in Accounting. Springer, 61-83.

Davenport TH and Kirby J. (2016) Just how smart are smart machines? MIT Sloan Management Review 57: 21.

Edmondson AC and McManus SE. (2007) Methodological fit in management field research. Academy of management review 32: 1246-1264.

Englund H and Gerdin J. (2014) Structuration theory in accounting research: Applications and applicability. Critical Perspectives on Accounting 25: 162-180.

Englund H, Gerdin J and Burns J. (2011) 25 Years of Giddens in accounting research: Achievements, limitations and the future. Accounting, Organizations and Society 36: 494-513.

Ghasemi M, Shafeiepour V, Aslani M, et al. (2011) The impact of Information Technology (IT) on modern accounting systems. Procedia - Social and Behavioral Sciences 28: 112-116.

Güney A. (2014) Role of Technology in Accounting and E-accounting. Procedia - Social and Behavioral Sciences 152: $852-855$.

He A. (2018) Response to Technological Innovation: The Impact of STEM Graduates on Employment Opportunities in Accounting Services Firms.

Hopwood AG. (1983) On trying to study accounting in the contexts in which it operates. Accounting, Organizations and Society 8: 287-305.

Huang F, Li H and Wang T. (2018) Information Technology Capability, Management Forecast Accuracy, and Analyst Forecast Revisions. Accounting Horizons 32: 49-70.

Janvrin DJ and Weidenmier Watson M. (2017) "Big Data": A new twist to accounting. Journal of Accounting Education 38: 3-8.

Kokina J and Davenport TH. (2017) The Emergence of Artificial Intelligence: How Automation is Changing Auditing. Journal of Emerging Technologies in Accounting 14: 115-122.

Latour B. (2005) Reassembling the social: An introduction to actor-network-theory: Oxford university press.

Lehner OM and Martikainen M. (2019) Special Issue on Digital Accounting ACRN Oxford Journal of Finance and Risk Perspectives. Oxford: ACRN Oxford, 104.

Neely MP and Cook JS. (2011) Fifteen Years of Data and Information Quality Literature: Developing a Research Agenda for Accounting. Journal of Information Systems 25: 79-108.

Okoli C and Pawlowski SD. (2004) The Delphi method as a research tool: an example, design considerations and applications. Information \& Management 42: 15-29.

Otley DT and Berry AJ. (1980) Control, organisation and accounting. Accounting, Organizations and Society 5: 231244.

Pearson TA and Singleton TWJIiAE. (2008) Fraud and forensic accounting in the digital environment. 23: 545-559.

Quattrone P. (2016) Management accounting goes digital: Will the move make it wiser? Management Accounting Research 31: 118-122.

Robson K and Bottausci C. (2018) The sociology of translation and accounting inscriptions: Reflections on Latour and Accounting Research. Critical Perspectives on Accounting 54: 60-75.

Sledgianowski D, Gomaa M and Tan C. (2017) Toward integration of Big Data, technology and information systems competencies into the accounting curriculum. Journal of Accounting Education 38: 81-93.

Taipaleenmäki J and Ikäheimo S. (2013) On the convergence of management accounting and financial accounting - the role of information technology in accounting change. International Journal of Accounting Information Systems 14: 321-348.

Vial G. (2019) Understanding digital transformation: A review and a research agenda. The Journal of Strategic Information Systems. 